\title{
Five-year experience of urethrocutaneus fistula repair in single tertiary referral hospital: a retrospective study
}

\author{
Adhitya Fajar Prasetya ${ }^{a}$, Johan Renaldo ${ }^{\mathrm{a}}$ \\ Corresponding author's email: adhityafajarprasetya@gmail.com

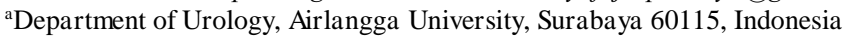

\begin{abstract}
Background: Hypospadias is a congenital defect that is often found in boys. There are many techniques of surgical correction which has been introduced since the 19th century. One of the post-operative complications in hypospadias is urethrocutaneous fistula.

Objective: This study aims at investigating the characteristics of UCF patients for five years in Dr. Soetomo General Hospital, Surabaya, East Java, Indonesia, according to age, previous hypospadias repair technique, and total fistula repair.

Material and Methods: All urethrocutaneous fistula patients who had been hospitalized in our institution were analyzed retrospectively in terms of age, previous hypospadias operation technique, and history of urethrocutaneous fistula repair. The design of our study is descriptive.

Results: Thirty-five urethrocutaneous fistula patients who had been hospitalized in Dr. Soetomo General Hospital, Surabaya, East Java, Indonesia were evaluated retrospectively. The patients are mostly 11-15 years-old (37.14\%). Fistula events are mostly occurred after undergoing tubularized incised plate (TIP) procedure $(77.14 \%)$. The majority of operated patients who have no recurrent UCF episodes are those who do not have a history of fistula repair.

Conclusion: The majority of urethrocutaneous fistula patients are 11-15 years-old and undergoing TIP procedures. Most of recovered operated UCF patients are those who have no previous history of fistula repair.
\end{abstract}

Keywords: urethrocutaneous fistula; hypospadias; tubularised incised plate

\section{Introduction}

Hypospadias is a congenital anomaly often found in male child, approximately 1 of 300 male births, ${ }^{1}$ and there is a tendency of incidence increase. ${ }^{2}$ The term hypospadias was invented by Galen in 2nd century AD to describe the condition where the urethral opening is located on the penile undersurface. ${ }^{3}$ Hypospadias incidence began to increase in 1970-1980 in Europe without any known cause. Despite of the lack of study on exact incidence of hypospadias in Indonesia, there are some studies scattered in many centers in Indonesia which find the incidence in great number. ${ }^{4}$

The modern surgical therapy of hypospadias had been introduced since 19th century, when Anger 
successfully repaired penoscrotal hypospadias with two longitudinal skin incisions, adopted from techniques used by Thiersch to repair epispadias. ${ }^{3}$ Nowadays, there are more than 400 operative techniques and modifications to repair hypospadias which have been described, showing that there is no universal technique for hypospadias repair. ${ }^{5}$

There are various complications of hypospadias operation, with urethrocutaneous fistula (UCF) becomes the commonest one. ${ }^{6}$ With the current incidence reaching $10-15 \%,{ }^{7}$ several factors contributing to its occurrence are opposing suture lines from neo-urethral and skin closure, distal obstruction from meatal stenosis or urethral stricture, turbulent urinary flow (eg. in diverticula), and impaired local vascularity. ${ }^{8}$ Smallsized UCF may spontaneously disappear, but most cases have to undergo surgical correction. ${ }^{9}$ The success rate of surgical correction varies, from $80.5 \%$ (Das et al. study), 97.3\% (Mohamed et al. study), and 97.5\% (Shirazi et al. study). ${ }^{10}$

Our study purpose is to address UCF patients' characteristics for 5 years in Dr. Soetomo General Hospital, according to age, previous hypospadias repair technique, and total fistula repair.

\section{Subjects and methods}

We analysed the data of 35 patients diagnosed with UCF who underwent surgical repair between January 2013-April 2018 in our institution. The study was conducted retrospectively with descriptive design, and the data collection was conducted by obtaining all patients' register numbers, then tracing in register books of operating theatre and printed or electronic medical records. We therefore recorded the patients' identities, such as age, previous hypospadias repair technique, and the amount of undergone UCF repair. The inclusion criteria were all patients who underwent UCF repair by urologists in our institution between 2013-2018, with the history of hypospadias operation. Most of UCF repair were conducted by 2 experienced uro-pediatric consultants. Patients were excluded from this research if the fistula was caused by other histories (such as urethral stricture, urethral trauma, epispadia, etc), the patients had developed UCF but never undergone any repair until the end of research period, and the repair was conducted by other specialists (eg. plastic or pediatric surgeons). The data would be descriptively analyzed, and its results were presented in the form of table and narration. 


\subsection{Ethical approval}

This study was approved by local ethics committee of the institute (number of certificate 1070/109/II/2019), in accordance with Helsinki Declaration of Principles. We ensured if all medical records have attached informed consent to extract data for scientific purpose.

\section{Results}

Between January 2013-April 2018, there were 35 UCF patients who underwent surgical repair. Table 1 classifies them according to age, history of hypospadias operation technique, and prior UCF repair, respectively. Prior UCF repair is defined as the number UCF repair done before the latest UCF repair. The prior-UCF-repair characteristic is further subdivided into the incidence of recurrence and recovery.

TABLE 1. Characteristics of UCF patients.

\begin{tabular}{|c|c|c|}
\hline Characteristics & $\mathrm{N}(\%)$ & $\begin{array}{c}\text { Total UCF patients } \\
(\%)\end{array}$ \\
\hline \multicolumn{3}{|l|}{ Age group } \\
\hline - $0-5$ years & $5(14.28)$ & \multirow{5}{*}{$35(100)$} \\
\hline - 6-10 years & $10(28.57)$ & \\
\hline - $11-15$ years & $13(37.14)$ & \\
\hline - $16-20$ years & $4(11.43)$ & \\
\hline - $>20$ years & $3(8.57)$ & \\
\hline \multirow{2}{*}{\multicolumn{3}{|c|}{ History of hypospadias operation technique }} \\
\hline & & \multirow{5}{*}{$35(100)$} \\
\hline - Tubularized incised plate (TIP) & $1(2.86)$ & \\
\hline - Onlay & $27(77.14)$ & \\
\hline - Koyanagi-Nonomura & $6(17.14)$ & \\
\hline & $1(2.86)$ & \\
\hline \multicolumn{3}{|l|}{ Prior UCF repair } \\
\hline - 0 time & $26(74.29)$ & \multirow{12}{*}{$35(100)$} \\
\hline Recurrence & $6(23.08)$ & \\
\hline Recovery & $20(76.92)$ & \\
\hline - 1 time & $2(5.71)$ & \\
\hline Recurrence & $2(100)$ & \\
\hline Recovery & $0(0)$ & \\
\hline - 2 times & $2(5.71)$ & \\
\hline Recurrence & $0(0)$ & \\
\hline Recovery & $2(100)$ & \\
\hline - $>2$ times & $5(14.28)$ & \\
\hline Recurrence & $1(20)$ & \\
\hline Recovery & $4(80)$ & \\
\hline
\end{tabular}

The following table explains operated UCF patients who were classified according to prior UCF repair which is further classified according to the hypospadias repair technique which had been done before. 
TABLE 2. Characteristics of operated UCF patients according to prior UCF repair number according to previous hypospadias operative technique.

\begin{tabular}{lccccc}
\hline \multirow{2}{*}{$\begin{array}{c}\text { Prior UCF } \\
\text { repair }\end{array}$} & TIP & Onlay & $\begin{array}{c}\text { Koyanagi- } \\
\text { Nonomura }\end{array}$ & Thiersch-Duplay & $\begin{array}{c}\text { Total UCF } \\
\text { patients }(\%)\end{array}$ \\
\cline { 2 - 5 } & $20(76.92)$ & $4(15.38)$ & $1(3.85)$ & $1(3.85)$ & $26(100)$ \\
0 time & $2(100)$ & $0(0)$ & $0(0)$ & $0(0)$ & $2(100)$ \\
time & $1(50)$ & $1(50)$ & $0(0)$ & $0(0)$ & $2(100)$ \\
2 times & $4(80)$ & $1(20)$ & $0(0)$ & $0(0)$ & $5(100)$ \\
\hline 2 times & & & & & \\
\hline
\end{tabular}

It can be assumed from the prior-UCF-repair characteristic in Table 3.1 that the total of non-recurrent (recovered) patients are $26(74.29 \%)$ and recurrent patients are 9 (25.71\%). Table 3 further details nonrecurrent operated UCF patients classified according to hypospadias operative technique and previous UCF repair. In the meanwhile, Table 4 gives a detail about recurrent operated patients with same classification. Note that the recovery and recurrence rates don't correspond to total UCF repair, as there are some patients with same total UCF repair who have developed recurrence and other have achieved recovery in the end of research period.

TABLE 3. Characteristics of non-recurrent operated UCF patients according to history of hypospadias operative technique and prior UCF repair number.

\begin{tabular}{lccccc}
\hline \multirow{2}{*}{$\begin{array}{c}\text { History of hypospadias repair } \\
\text { technique }\end{array}$} & \multicolumn{3}{c}{ Prior UCF repair $(\mathrm{N}(\%))$} & \multirow{2}{*}{$\begin{array}{c}\text { Total UCF patients } \\
(\%)\end{array}$} \\
\cline { 2 - 4 } & 0 time & 1 time & 2 times & $>2$ times & $19(73.08)$ \\
TIP & $14(73.68)$ & $0(0)$ & $1(5.26)$ & $4(21.05)$ & $5(19.23)$ \\
Onlay & $4(80)$ & $0(0)$ & $1(20)$ & $0(0)$ & $1(3.85)$ \\
Koyanagi-Nonomura & $1(100)$ & $0(0)$ & $0(0)$ & $0(0)$ & $1(3.85)$ \\
Thiersch-Duplay & $1(100)$ & $0(0)$ & $0(0)$ & $0(0)$ & $26(100)$ \\
\hline Total UCF patients $(\%)$ & $20(76.92)$ & $0(0)$ & $2(7.69)$ & $4(15.38)$ & \\
\hline
\end{tabular}

TABLE 4. Characteristics of recurrent operated UCF patients according to history of hypospadias operative technique and prior UCF repair number.

\begin{tabular}{lccccc}
\hline \multirow{2}{*}{$\begin{array}{c}\text { History of hypospadias repair } \\
\text { technique }\end{array}$} & \multicolumn{3}{c}{ Prior UCF repair $(\mathrm{N}(\%))$} & \multirow{2}{*}{$\begin{array}{c}\text { Total UCF } \\
\text { patients }(\%)\end{array}$} \\
\cline { 2 - 5 } & 0 time & 1 time & 2 times & $>2$ times & $8(88.89)$ \\
TIP & $6(75)$ & $2(25)$ & $0(0)$ & $0(0)$ & $1(11.11)$ \\
Onlay & $0(0)$ & $0(0)$ & $0(0)$ & $1(100)$ & $0(0)$ \\
Koyanagi-Nonomura & $0(0)$ & $0(0)$ & $0(0)$ & $0(0)$ & $0(0)$ \\
Thiersch-Duplay & $0(0)$ & $0(0)$ & $0(0)$ & $0(0)$ & $9(100)$ \\
\hline Total UCF patients $(\%)$ & $6(66.67)$ & $2(22.22)$ & $0(0)$ & $1(11.11)$ & \\
\hline
\end{tabular}

\section{Discussion}

The age of UCF patients operated for five years in our institution mostly ranged between 11-15 years, ie. 13 patients $(37.14 \%)$, and the fewest of them were more than 20 years, ie. 3 patients $(8.57 \%)$. From literature tracing, there is no data presenting optimal age for UCF repair yet. However, Urology Committee of the 
American Academy of Pediatrics states that the optimal age for elective surgery in genitalia is within six months until four years, considering the patient's emotional and psychological factors. ${ }^{11}$ From our institution's data, the prevalence of 11-15 years may be caused by the low education of the parents, making their awareness to bring their son to urology clinic for examination is minimal and economical obstacle also becomes contributing factor in operation delay.

Most of hypospadias patients who developed UCF in our institution were they who had been operated with TIP technique, ie. 27 patients $(77.14 \%)$. TIP is the most widely used technique to repair hypospadias, ${ }^{12}$ and often bears fistula complication. ${ }^{13}$ For post-TIP UCF, the incidence varies from $46.15 \%$ (Sheng et al, 2018), ${ }^{9}$ $61.1 \%$ (Yassin et al, 2011), ${ }^{14}$ and, respectively, 54.9\% in success group and $66.3 \%$ in failed group in Abdullaev et al study (2021). ${ }^{15}$ In our study, the high prevalence of post-TIP patients who developed urethrocutaneous fistula may be attributed to the fact that TIP is the mostly used hypospadias repair technique compared to other surgical repair techniques of hypospadias. Besides, TIP technique is likely to generate the higher pressure in neo-urethra since its diameter may be small and inelastic. ${ }^{16}$ Statistical analysis by Chung et al (2012) concluded that the fistula incidence had more relations with the hypospadias' location, when the repair technique of hypospadias, suture type and techniques had no relation with UCF formation. ${ }^{17}$

Most of operated hypospadias patients in Dr. Soetomo General Hospital developed into primary UCF, who underwent one-time operation (meaning that there was no prior UCF repair), ie. 26 patients $(74.29 \%)$. The fewest of them would undergo two- and three-time fistula repair (meaning that there was history of one- and two-time repair, respectively), each of which were two patients (5.71\%). Waterman et al (2002) reported there was no significant difference in repair outcome while comparing several variables, for example stent or catheter utilisation, optical magnification, patient's age, and interval between surgery at the time of UCF repair, early hypospadias type, and history of total fistula repair. The successful rate of fistula repair depends on some basic principles, which have to be avoided in inflamed tissue, correction of distal obstruction, tension-free urethral closure with absorbable suture, and the urethral repair closure with well-vascularised tissue. $^{14}$

From 35 UCF repair conducted between January 2013-April 2018, there were 9 patients (25.71\%) who experienced recurrence, with other 26 patients $(74.29 \%)$ who recovered. From each of the groups, it was found that the hypospadias repair previously utilised were predominantly TIP, given that TIP is the mostly used hypospadias repair technique in our institution.

The etiology of UCF recurrence is poorly understood. Beside of surgical technique deficiency, the impaired vascularisation in the surrounding skin which develops into scar tissue becomes the most plausible explanation. Srivastava et al (2011) reported that fistula repair with the same procedure in the skin which becomes scar tissue contributes to the increased potential recurrence. ${ }^{18}$ As there was no findings of stricture or meatal stenosis during most UCF repair in our institution done by two experienced uro-pediatric consultants, it could be assumed that most post-hypospadias repair UCF cases in our institution were caused by impaired vascularisation.

Small-caliber fistula may primarily be closed without adjusting to diameter of urethral lumen. Larger fistula needs closure with trap-door or island flap from penile shaft skin. The better outcome is generally achieved when the second layer or flap coverage is utilised, especially in recurrent UCF case. Skin coverage may be obtained with some methods to avoid overlapping urethral and skin suture lines. ${ }^{6}$ 
Although the repair is well done, the risk of fistula recurrence more than $20 \%$ may occur, ${ }^{6}$ which can be diminished by tissue interpositioning between neo-urethra and the skin. Neo-urethra may be covered with various tissues, including spongious tissue located lateral of neo-urethra, pedicled external spermatic fascia, scrotal adipose tissue, spermatic cord, dartos and tunica vaginalis flaps. ${ }^{19}$ De-epithelialised flap repair becomes another promising technique. Urinary diversion is unnecessary for simple repair; for larger repair, it is necessary to divert urine with silicone catheter for 7-10 days. Eventually, in case of severe fistula, buccal mucous graft (BMG) is used with various success.6 Kim et al (2020) suggested that BMG is only applied to highly selected patients, as its post-operative complications is higher than staged approach. ${ }^{20}$

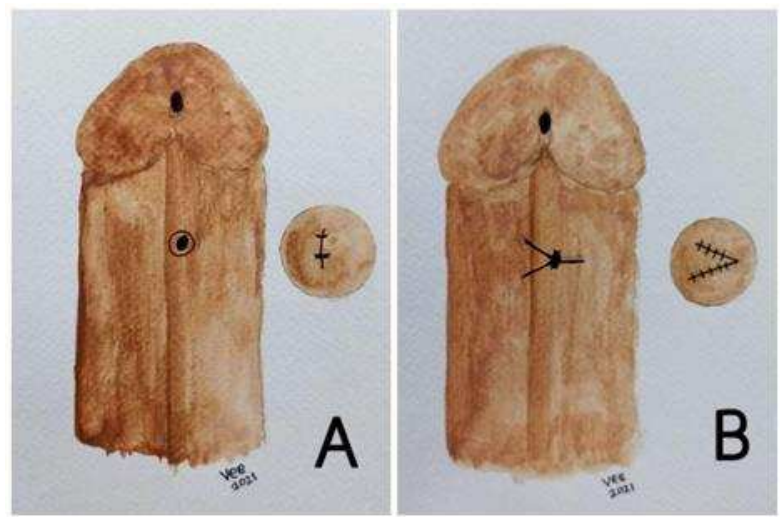

Fig. 1. UCF repair technique after hypospadias operation commonly used in our institution: (a) excision and primary closure technique, (b) Y-V skin advancement after excision and closure of fistula.

We acknowledge several limitations, which could be attributed to the retrospective nature of our study, which may generate information bias. The result of our study may not exactly mirror the study from a larger heterogeneous because it is conducted in a single institution (which makes our study population smaller). It is also partly caused by the short period of this retrospective study (five years). Because of that, our study isn't powered adequately to query all potential predictive variables of interest.

\section{Conclusion}

In summary, the incidence of UCF patients operated in our institution is mostly found in 11-15 years old $(37.14 \%)$, most of them had undergone TIP hypospadias repair $(77.14 \%)$. Majority of UCF had no history of previous fistula repair, indicating that primary fistula cases reached majority during the study. In 5-year period, the rate of recurrence reached $25.71 \%$. Further investigation is needed to minimalize the recording bias with prospective approach and multicenter study. It is better to form special team for comprehensive management of hypospadias and its complications so that it enables a better study.

\section{References}

McAninch JW, Lue TF. Smith \& Tanagho's General Urology: 19th Edition. San Francisco: McGraw-Hill, 2020.

Andersson M, Doroszkiewicz M, Arfwidsson C, Abrahamsson K, Holmdahl G. Hypospadia repair with tubularized incised plate: does the obstructive flow pattern resolve spontaneously? J Ped Urol 2011; 7: 441-5.

Hadidi AT. History of hypospadias: lost in translation. J Ped Surg 2017; 52: 211-7. 
Krisna DM, Maulana A. Hipospadia: bagaimana karakteristiknya di Indonesia? Berk Ilm Kedokt Duta Wacana 2017 ; 2 (2): $325-33$.

Stein R. Hypospadias. Eur Urol Suppl 2012; 11: 33-45.

Taneja SS, Shah O. Taneja's Complications of Urologic Surgery: Diagnosis, Prevention, and Management (Fifth Edition). New York City: Elsevier, 2018.

Fariz M, Rodjani A, Wahyudi I. Risk factors for urethrocutaneous fistulas formation after one stage hypospadias repair. Indonesian J Urol 2011; 18 (2): 48-54.

Docimo SG, Canning D, Khoury A, Pippi Salle JL. The Kelalis-King-Belman Textbook of Clinical Pediatric Urology: Sixth Edition. Boca Raton: CRC Press, 2018.

Sheng X, Xu D, Yu Y, Chen J, Qi J. The risk factors of urethrocutaneous fistula after hypospadias surgery in the youth population. BMC Urol 2018; 18: 64.

Das SK, Hasina K, Huq MAU, Alam SMS, Adil SA, Islam KMS. Outcome of urethrocutaneous fistula repair after hypospadias surgery. Bang Med J Khulna 2019; 52: 3-6.

Duarsa GWK, Nugroho TD. Characteristics of hypospadias cases in Sanglah General Hospital, Bali-Indonesia: a descriptive study. Bali Med J 2016; 5 (1): 13-6.

Leslie B, Jesus LE, El-Hout Y, Moore K, Farhat WA, Bägli DJ et al. Comparative histological and functional controlled analysis of tubularized incised plate urethroplasty with and without dorsal inlay graft: a preliminary experimental study in rabbits. J Urol 2011; 1631-7.

Naumeri F, Munir MA, Ahmad HM, Sharif M, Awan NU, Butt G. Comparison of urethrocutaneous fistula rate after single dartos and double dartos tubularized incised plate urethroplasty in pediatric hypospadias. Cureus 2021; 13 (2): e13378.

Yassin T, Bahaaeldin KH, Husein A, El Minawi H. Assessment and management of urethrocutaneous fistula developing after hypospadias repair. Ann Ped Surg 2011; 7: 88-93.

Abdullaev Z. Agzamkhodjaev S, Chung JM, Lee SD. Risk factors for fistula recurrence after urethrocutaneous fistulectomy in children with hypospadias. Turk J Urol 2021; 47 (3): 237-41.

Widjajana DP, Wahyudi SS, Sutejo IR. The relation of hypospadias types, ages, and surgical techniques for urethrocutaneous fistula complication in child hypospadias cases. Indonesian J Urol 2019; 26 (2): 214-8.

Chung JW, Choi SH, Kim BS, Chung SK. Risk factors for the development of urethrocutaneous fistula after hypospadias repair: a retrospective study. J Urol 2011; 185: 2483-6.

Srivastava RK, Tandale MS, Panse N, Gupta A, Sahane P. Management of urethrocutaneous fistula after hypospadias surgery: an experience of thirty-five cases. Indian J Plast Surg 2011; 44 (1): 98-103.

Fahmy O, Khairul-Asri MG, Schwentner C, Schubert T, Stenzl A, Zahran MH et al. Algorithm for optimal urethral coverage in hypospadias and fistula repair: a systematic review. Eur Urol 2016; 70 (2): 293-8.

Kim SW, Lee YS, Han SW. Buccal mucosa tube graft for failed hypospadias repair: worth it or not? Ped Urol 2020; 146: 196-200. 